\title{
Estado, juventude e narrativas do sistema socioeducativo: direitos humanos, saúde e políticas sociais
}

\author{
State, youth and socio-educational system narratives: \\ human rights, public health and social policies
}

Diego Sousa de Carvalho (https://orcid.org/0000-0003-4094-3436) ${ }^{1}$

${ }^{1}$ Programa de Pós-

\begin{abstract}
This work, extracted from the doctoral research of the author, aims to discuss, from the reports of socio-educational system professionals, the access to State politics and programs performed by youth in conflict with the law attending to socio-educational system. In this research, 14 professionals who work in periphery regions, at the South Zone of São Paulo were interviewed, using the methodological proposal of "narrative policies". From the reports, we can see ambiguities of proposals and state interventions, configuring the "double discipline" of State, evidencing the insufficiency and the disinvestment in social security and social assistance policies, meanwhile occurs the production of an apparatus of repressive measures. We discuss the theme related to the field of public health and the importance of the bonds between professionals and youth attending to socio-educational system.
\end{abstract}

Key words State, Socio-educational programs, Social public policies, Youth human rights
Resumo O presente artigo, extraído da pesquisa de doutoramento do autor, busca, a partir dos relatos de profissionais ligados à rede de proteção socioassistencial, discutir o acesso de jovens em atendimento socioeducativo em meio aberto às politicas e programas do Estado. Foram entrevistados 14 profissionais atuantes em bairros periféricos da Zona Sul do Município de São Paulo, utilizando a proposta metodológica das "políticas de narratividade". A partir dos relatos, percebe-se ambiguidades de propostas e de intervenção do Estado, configurando a "dupla disciplina" do Estado, por meio da qual, evidencia-se a insuficiência e $o$ desinvestimento em políticas previdenciárias e socioassistenciais, ao mesmo tempo em que ocorre a produção de um aparato de medidas repressivas. Discutimos as relações da temática com o campo da saúde pública, e pensamos a importância dos vínculos constituídos entre os profissionais e os jovens em cumprimento de medidas socioeducativas em meio aberto.

Palavras-chave Estado, Atendimento socioeducativo, Políticas sociais, Direitos humanos da juventude 


\section{Introdução}

Com o estabelecimento do Estatuto da Criança e do Adolescente (ECA) ${ }^{1}$, mudanças na abordagem e condutas são exigidas sobre adolescentes e jovens em práticas de ato infracional. O jovem em conflito com a lei é uma categoria jurídica que desponta no ordenamento legal brasileiro, em substituição ao termo "menor". Ainda nesse sentido, em complemento ao Estatuto, inicia-se em 2006 e consolida-se a partir de 2012, o Sistema Nacional de Atendimento Socioeducativo (SINASE) $)^{2}$. Prerrogativa desta política é trabalhar ações sociais e educativas em conjunto na responsabilização legal do adolescente infrator. Tal premissa interpreta-se em conformidade à proteção integral, e diz respeito a um compromisso entre família, comunidade e poder público para defesa e garantia de direitos humanos fundamentais de crianças, adolescentes e jovens.

Partindo das concepções prescritas nestes mecanismos, existe uma prerrogativa para a constituição subjetiva e cidadã de crianças, adolescentes e jovens. Cabendo respostas dos diferentes setores do poder público, familiar e sociocomunitário para resguardá-las. Nesta concepção, o ato em conflito com a lei praticado por adolescente denota o desencontro num compromisso coletivo, cujas respostas legais acionarão os entes envolvidos, tendo em vista a sociabilidade destes sujeitos-cidadãos como parte de seu processo de responsabilização numa repactuação dessas múltiplas instâncias.

O presente artigo expõe reflexões decorrentes de pesquisa de doutoramento ${ }^{3}$ no programa e área de Saúde Pública, junto à Universidade de São Paulo, articulando elementos analíticos no campo de estudos das políticas públicas de saúde e assistência social, assim como, das ciências sociais, pensando na adolescência e juventude como objeto discursivo de políticas específicas e de atenção de setores da sociedade e do Estado, assim como de seus representantes institucionais.

Acompanharemos por meio de relatos de profissionais do sistema socioeducativo em meio aberto o atravessamento das políticas públicas em seu acesso, ou falta do mesmo, os espaços onde o Estado atua menos num papel propositivo, ou a despeito, propõe por meio da exclusão.

Temos também a intenção de trazer ao discurso pautas frequentemente obnubiladas quando se tratam das políticas para a juventude, especialmente, em conflito com a lei, como os altos índices de mortalidade, a vitimização promovida por ações policiais, a pobreza e marginalização de parte desta população. Considerando que o número de homicídios entre indivíduos de 15 a 24 anos é maior do que entre outras faixas etárias. Com relação ao Município de São Paulo, esta taxa encontra-se diretamente relacionada à ação policial em regiões periféricas ${ }^{4,5}$.

As hipóteses que tínhamos, no desenvolvimento deste estudo, eram da existência, nos discursos do sistema de medidas socioeducativas, de uma compreensão do Estado e da sociedade, menos como um sistema ordenado de garantias, mais como um sistema pró-beneficente, onde as soluções sejam individualizantes para as trajetórias de vida do público em atendimento, particularmente, dos jovens negros moradores de periferias da Zona Sul de São Paulo, circunstanciados pela situação conflitiva com a lei. Por fim, entendemos que encarceramento e/ou violências são respostas mais frequentes do Estado com relação à população jovem em situação vulnerável, em especial os jovens negros. A pesquisa pretendeu desvelar, a partir de relatos do trabalho socioeducativo, narrados pelos profissionais do sistema de medidas socioeducativas, como repercutem essas relações.

A pesquisa teve como objetivo geral: compreender, a partir dos relatos de profissionais do sistema socioeducativo, o acesso aos programas e políticas do Estado pela juventude em conflito com a lei e moradora de periferias, na Zona Sul do Município de São Paulo.

E como objetivos específicos: discutir, a partir das concepções e descrições feitas por estes profissionais, a respeito das dinâmicas do trabalho, $\mathrm{o}$ trânsito das políticas socioeducativas junto às demais políticas sociais, e sua relação com os jovens em atendimento nos serviços no que tratam aos contextos sociais, familiares, e territoriais destes.

Levantar, a partir desses relatos, casos e histórias do atendimento socioeducativo, narradas pelos profissionais do sistema socioeducativo, que ofereçam contornos que possibilitem a discussão sobre o acesso / exclusão dos jovens em atendimento socioeducativo às políticas sociais $\mathrm{e}$ aos direitos.

\section{O trabalho socioeducativo}

O trabalho socioeducativo, de acordo com o previsto nos instrumentos de proteção aos direitos dos adolescentes, principalmente o ECA e o SINASE, atende a jovens encaminhados pelo Poder Judiciário nas faixas etárias de 12 a 21 anos (quando cumprem medida aplicada antes de completarem 18 anos de idade). 
O sistema de medidas socioeducativas em meio fechado é desenvolvido pelo governo do Estado. Atende jovens encaminhados para cumprirem medidas privativas de liberdade: medidas de internação ou de internação provisória. Esse sistema é substitutivo ao modelo FUNABEM-FEBEM, busca em sua proposta realizar atividades educativas e formativas para os jovens internos.

Já o sistema de medidas socioeducativas em meio aberto, sobre o qual abordaremos neste artigo, atende jovens em cumprimento de medidas de restrição de liberdade, encaminhados pelo Poder Judiciário com demandas específicas. Os profissionais entrevistados na pesquisa atuam neste âmbito. A gestão desses serviços é municipalizada, conforme previsão do SINASE.

No município de São Paulo as atividades são desempenhadas por organizações da sociedade civil sem fins lucrativos, atuantes nos diversos territórios. A administração e o financiamento cabem à Prefeitura Municipal, por meio da Secretaria Municipal de Assistência e Desenvolvimento Social (SMADS), através de suas coordenadorias de Proteção Social Especial, junto aos distritos.

O trabalho envolve acolhimento dos jovens, quando egressos do sistema judiciário; a elaboração de um Plano Individualizado de Atendimento (PIA) em conformidade às medidas indicadas também pelo judiciário; o apoio e orientação ao jovem em atividades como retirada de documentos, busca de emprego, inscrição em cursos e matrícula escolar, inclusão em serviços de saúde e assistência social; atendimentos individuais para orientação e acompanhamento por um dos profissionais de nível superior referendados; atendimentos em grupo e realização de grupos de discussão temáticos e grupos de famílias; visitas domiciliares; atividades de lazer, entre outras.

\section{Métodos}

Trata-se de estudo exploratório de abordagem qualitativa utilizando entrevistas semiestruturadas em grupos. A etapa de coleta de dados ocorreu de janeiro a agosto de 2018, em dois distritos em regiões periféricas na Zona Sul do Município de São Paulo, junto a serviços de atendimento socioeducativo em meio aberto (SMSE/MA), conveniados à rede de proteção social especial da assistência social municipal. A escolha dos mesmos justifica-se pelos indicadores sociais, apontando vulnerabilidades regionais e elevados índices de infracionalidade, violência e letalidade juvenil.
O cronograma das visitas seguiu a disponibilidade da gestão e das equipes locais para atender ao pesquisador, sendo que a maioria das visitas aconteceu em dias da semana reservados pelos serviços para reuniões em equipe.

Foram entrevistados 14 profissionais (2 destes eram os gestores das respectivas equipes) que atuam em serviços de medida socioeducativa em meio aberto (SMSE/MA). O perfil dos colaboradores é analisado conforme Tabela 1. A maioria dos participantes é do gênero feminino. A média de idade entre os participantes é 34 anos de idade. A maior parte dos trabalhadores vive na Região Sul do Município, mesma região dos serviços em que atua. Os entrevistados atenderam a encontros que ocorreram em seus próprios locais de trabalho. Foi priorizada a aplicação de entrevistas coletivas, (somente uma das entrevistas realizadas foi individual, devido à necessidade de agenda com o profissional entrevistado, que foi o primeiro em seu setor acordando em participar, mas que estaria de férias quando da realização das entrevistas coletivas).

O único critério apresentado aos profissionais era sua participação por iniciativa própria.

A escolha pela Zona Sul do Município de São Paulo como região pesquisada se relaciona a seus elevados índices de vulnerabilidades, entendendose a influência destes pensando o tema estudado.

De fato, a região Sul deu relevo a questões que implicam nos modos como se organizam as políticas, os sujeitos e as instituições, e garantiu relevância e especificidades - localidade - às discussões tratadas em campo e ora analisadas, pensando os altos índices de violência juvenil, mas também que as condições de vida dos sujeitos, em diferentes esferas, estão relacionadas aos fenômenos abordados.

A pesquisa foi submetida e aprovada pelo Comitê de Ética da Faculdade de Saúde Pública da Universidade de São Paulo.

Foram utilizados como instrumentais Termos de Consentimento Livre e Esclarecido (TCLE), apresentados em duas vias, sendo uma delas disponibilizada para os entrevistados e a outra para o entrevistador, e a coleta de dados ocorreu com a ciência e anuência das instituições e de seus gestores.

\section{Histórias em vez de casos, narrativas e devires}

[...] Eu acho que todos (os casos) afetam. Acho que, de uma maneira geral, a gente se sente afetada sempre. Cada história, a gente fala caso, mas tem uma história, são pessoas, né? (Oyá). 
Tabela 1. Perfil dos respondentes por gênero; idade; região de residência; área de formação; e tempo de atuação no serviço de medidas socioeducativas de meio aberto.

\begin{tabular}{|c|c|c|c|c|c|c|c|c|c|}
\hline $\begin{array}{c}\text { Por } \\
\text { gênero }\end{array}$ & $(\%)$ & Por idade & (n) & $\begin{array}{l}\text { Por região } \\
\text { de residência }\end{array}$ & $(\%)$ & $\begin{array}{l}\text { Por área de } \\
\text { formaçãa }{ }^{*}\end{array}$ & (\%) & $\begin{array}{l}\text { Por tempo de } \\
\text { atuação no atual } \\
\text { SMSE/MA }\end{array}$ & $(\%)$ \\
\hline Feminino & 50 & Maior & 44 & $\begin{array}{l}\text { Mesma região do } \\
\text { trabalho }\end{array}$ & 50 & Ciências sociais & 14,2 & Menos de 1 ano & 31 \\
\hline \multirow[t]{5}{*}{ Masculino } & 50 & Menor & 24 & Outra região & 36 & Comunicação & 7,1 & De 1 a 2 anos & 31 \\
\hline & & Média & 34,7 & Outro município & 14 & Pedagogia & 14,2 & De 2 a 4 anos & 8 \\
\hline & & & & & & Psicologia & 14,2 & De 4 a 6 anos & 15 \\
\hline & & & & & & Serviço social & 14,2 & De 6 a 9 anos & 15 \\
\hline & & & & & & Não informado & 35,7 & & \\
\hline
\end{tabular}

${ }^{*}$ A composição das equipes técnicas dos serviços SMSE/MA, no Município de São Paulo, no que trata dos profissionais de nível superior, estes são contratados como "Técnicos sociais" ou "Técnicos socioeducativos", independentemente de sua área de formação.

Fonte: Elaborado pelo autor, 2021.

A fala extraída do relato da entrevistada aponta-nos um caminho para que compreensão que, para além do diálogo acadêmico-científico, não se trata somente de questões sociais narradas, mas, em primeiro lugar, da vida de pessoas. A entrevistada entende que, sendo mais histórias que casos, como tendemos a tratar nas discussões acadêmicas e científicas, é possível destacar, "lembrar" que ali, depois da discussão, há pessoas reais.

Dito isto, seguem neste texto, sob a nomenclatura de histórias, narrações de episódios de vidas. Sujeitas e sujeitos que vivenciam as vulnerabilidades e violações de direitos tratadas aqui, mas que estão para além do que podemos falar a seu respeito. Que estabelecem contratos, têm desejos, virtudes, cometem erros e infrações à lei, que se articulam, lutam, amam, resistem, têm objetivos que são alcançados ou frustrados. Dispõem de dimensões que ultrapassam seu conflito com a lei e sua relação com o Estado e seus agentes, de uma ordem dinâmica que é própria da vida, portanto, mais profunda, mais legítima e menos breves do que alcança nossa abordagem.

Mais que isso, os personagens que protagonizam tais histórias não são tampouco tais histórias. Estão sendo "contados" pelos profissionais e ora recontados neste trabalho.

A noção de "vontade de verdade" é nos apresentada pela obra foucaultiana ${ }^{6}$, trata que, nos discursos, na produção de saberes e conhecimentos, por meio desta, busca-se o "discurso verdadeiro", que se insira e se desloque nas relações de poder. Esse deslocamento de poder que circula na produção de saberes é um dos grandes interesses da obra foucaultiana, e o autor dirá que essa vontade de verdade participa de um sistema historicamente localizado, re-produtor de exclusões. Sutilmente, as tecnologias discursivas que produzem verdades e "não-verdades" mascaram essa vontade de verdade que as engendram, as mesmas que perfazem o saber acadêmico.

Pensando a escolha metodológica a partir de um ethos na pesquisa em saúde, buscamos em Passos e Benevides a proposta de investimento numa política de narratividade ${ }^{7}$. Estes autores apontam que:

Os dados coletados a partir de diferentes técnicas [...] indicam maneiras de narrar - seja dos participantes ou sujeitos da pesquisa, seja do pesquisador ele mesmo - que apresentam os dados, sua análise e suas conclusões segundo certa posição narrativa ${ }^{7}$.

É importante ainda destacar que a construção de uma narrativa passa pela "renarrativação do mundo" ${ }^{8}$, isto é, as narrativas remetem, ao mesmo tempo, à experiência do narrador e do ouvinte/leitor e aos acontecimentos narrados situados espacial e temporalmente. O conceito de narrativa é descrito, a princípio pelo pensador Walter Benjamin, que afirma o desinteresse da narrativa na transmissão do "puro em si da coisa narrada”, possibilitando um "mergulho" na vida do narrador e a posterior retirada deste ${ }^{9}$.

Na presente análise, evidencia-se a opção pela narrativa como método de análise e fonte de dados, de forma que, longe de pensar a "vontade de verdade" a qual denuncia Foucault, propõe-se captar algo que se apresenta no devir, conceito que o antropólogo João Biehl extrai do pensamento deleuzeano, implicando para a metodologia das pesquisas sociais em atentar "aos devires humanos"10,11, possibilitando: 


\section{Resultados e discussão}

\section{A história de Onira, a mãe-filha}

Dos 120 jovens inscritos naquele serviço de medidas socioeducativas em meio aberto (SMSE/ MA), havia seis meninas na época da pesquisa. Poucas em número, mas, segundo Dandalunda, a profissional que colabora com esta narrativa, a despeito de poucos casos, estes eram "bombásticos", "muito complexos".

Dandalunda é a referência técnica responsável pelo acompanhamento de medida de Onira, que chegou aos 16 anos naquele serviço. $\mathrm{Na}$ época estava grávida de seu segundo filho, que, à época do relato, contava com 4 meses. Onira perdeu a guarda do primeiro filho ao ser institucionalizada na Fundação Casa, e a criança encontra-se aos cuidados da família paterna.

Passam por "extrema necessidade", conta a profissional, demandas "de comida até moradia".

Onira vive com o atual companheiro, seu relacionamento é descrito pela técnica como "conflituoso". Conta que o casal, em uma das ocasiões preocupou a equipe, que, num primeiro momento, pensou que o casal estivesse discutindo. "Só tavam jogando dama, a gente pensou que eles tavam se matando" (Dandalunda).

Onira foi diagnosticada com sífilis durante a gestação e, no momento do parto, a criança fora infectada. Dandalunda afirma ter tido conversas com a equipe de saúde e desconfia de possíveis negligências da Unidade Básica de Saúde.

Conforme o Boletim Epidemiológico dedicado ao tema da Sífilis ${ }^{12}$, tem havido, nos últimos anos, grande aumento dos casos de sífilis em gestantes, congênita e adquirida. Tendência mais significativa a partir de 2011; somente no Estado de São Paulo, houve um aumento de até $800 \%$

das notificações de novas infecções no período entre 2011 e 2016. Ainda, a partir de 2011, houve tendência ao aumento de casos em jovens gestantes na faixa etária entre 15 e 19 anos. O tratamento para esta infecção sexualmente transmissível é feito a partir da administração de medicamentos à base de penicilina benzatina, matéria prima em desabastecimento no mesmo período, agravando a ocorrência das novas infecções. O tratamento considerado adequado para gestantes infectadas por sífilis, com a administração de penicilina benzatina, é iniciado até 30 dias antes do parto, os casos que não correspondem a este critério são considerados tratados inadequadamente ${ }^{12}$ :

Acho que talvez no pré-natal não houve esse tratamento (para a sifilis) que deveria ocorrer. $O$ bebê nasceu, teve que tomar sei lá eu quantas (injeções de) Benzetacil (antibiótico que contêm penicilina benzatina) (Dandalunda).

A profissional descreve a situação como uma “ausência generalizada do Estado”. Ainda, o bebê apresenta sintomas de um agravo dermatológico, com manchas na pele. E Onira também apresentava um cisto na garganta então não tratado:

[...] Ela pede no ônibus. Infelizmente, tem feito isso. Dentro do transporte coletivo. Ela pede. Ela nem quer levar, mas com quem ela vai deixar [o filho]? O marido sai pra vender no ônibus, ela tem que sair pra pedir. Com quem vai ficar a criança? A mãe dela se nega. E ela vê a situação apertar. A única alternativa que ela tem é sair de casa [para pedir]... Ou ela fica em casa, ela pode optar por essa alternativa, mas ela fica sem ter dinheiro pra pagar o aluguel (Dandaluda).

O serviço conseguiu junto ao CREAS (Centro de Referência Especializado de Assistência Social) garantir cestas básicas para Onira. Porém, sua inscrição no Programa Bolsa Família (PBF), não pode ser concluída. Os profissionais explicam que a mãe de Onira já tem essa inscrição no Programa:

A mãe fez o cadastro e a família (materna) recebe. A partir do momento que ela receber, a mãe não vai receber mais. Mãe e filha têm uma relação de distanciamento, a mãe não quer nem saber [...] Ela não pode desvincular ( $a$ inscrição da mãe no $P B F)$, porque é menor de idade. E não pode pedir outro cadastro, porque dá cruzamento de dados (Dandaluda).

A equipe descreve a última visita domiciliar realizada, nesta ocasião, perguntam a Onira sobre seu filho mais velho: "Ah a gente foi visitar, tá com minha ex-sogra". Onira visitara o filho antes do Natal e, no mês de abril, os profissionais a questionaram sobre sua intenção de voltar a ver o 
filho. "Sim, vou (voltar a visitá-lo), mas não posso voltar agora, porque eu fui e ele me pediu um carrinho. E eu não vou voltar lá sem o carrinho" (Onira).

\section{A história do contador de histórias}

A entrevistada Ewá começa a descrever o caso de um jovem a quem apelidou de "meu contador de histórias", devido às várias "histórias" que ele conta semanalmente, alegando motivos para não comparecer ao atendimento da medida socioeducativa. "Toda semana, ele chega e me conta uma história. Eu fico, meu Deus, qual a parte que é verdade dessa história que ele tá me contando, sabe?" (Ewá).

Vunji, então com 14 anos, filho de uma lavadeira - a informação da profissão de sua mãe nos produzira grande estranhamento. Ewá explica que a mulher pega roupa dos vizinhos para lavar, "uma profissão em desuso", como destaca a entrevistada, que por vezes a deixa sem ofertas de trabalho. Atendidos pelo Programa Bolsa Família, Ewá informa que esta seria a maior parte da renda mensal.

Vivendo em um território de alta vulnerabilidade social e ambiental, na Zona Sul do Município, numa região ocupada por moradias irregulares em área de proteção de mananciais, "depois da ponte", seguindo por uma estrada de terra às margens da represa Guarapiranga. De forma que o serviço de medida não conseguiu concluir a visita domiciliar.

Em dado momento, Vunji conta à técnica de referência que está traficando. Posteriormente, afirma não estar mais morando com sua mãe, que teria se mudado para o Piaú, e com mais algum tempo, o garoto deixa de comparecer e de entrar em contato.

É prática da medida socioeducativa de liberdade assistida o comparecimento aos serviços para atendimento junto aos profissionais de referência, a frequência é determinada pelo Poder Judiciário na imposição da medida. Após um mês de faltas, o serviço encaminha a informação de descumprimento da medida ao Poder Judiciário. Ewá conta de sua angústia, para além das dificuldades de acesso à região onde vivia, não tinha o contato telefônico ou o novo endereço de Vunji.

Pouco tempo antes de completar um mês de faltas, Vunji retorna ao serviço, dizendo que está morando com seu pai agora. Conta que voltou ao tráfico, o que motivou o distanciamento de sua mãe e sua mudança de Estado. Esta o teria feito prometer parar de traficar, e ele não cum- prira. Novamente, a profissional se afirma diante de um posicionamento complexo. Como dirá que ele não deve traficar? Devido à sua idade, ao local onde vive, são difíceis as circunstâncias de empregabilidade e insuficientes os programas de inclusão. Devido às suas condições de vida, à falta de renda familiar, o tráfico emerge como mais uma solução informal de empregabilidade local, tal qual a lavanderia de roupas às margens da Represa.

Como retirar esse jovem da informalidade do tráfico e garantir acesso à renda de maneira formal e preservando seus direitos?

Vunji, o "contador de história", e também Ewá atuam nas políticas de narratividade. Para além de um regime de produção de verdadeiro e exclusão do falso, "não mais pensada exclusivamente a partir de um centro do poder" - a medida imposta judicialmente, o trabalho de Ewá em função do Estado -, "a política (de narratividade) se faz também em arranjos locais, por microrrelações" . Vunji resiste nos contornos situacionais que faz, conta histórias para se adaptar às dinâmicas da regulação do Estado. Por sua vez, Ewá, enquanto recolhe os fragmentos das histórias contadas por Vunji, busca soluções para além das saídas institucionais, tentando preservar o jovem das consequências destas.

$\mathrm{O}$ vínculo desenvolvido junto à profissional muitas vezes é posto à prova, pelo jovem e pelas condições concretas de atuação. Ewá conta que, naquela mesma semana em que ocorreu a entrevista, ele chegou: "Eu faltei porque eu tô trabalhando com meu pai”. Mas há uma incerteza entre suas histórias, quais são verdadeiras? Qual o caminho para se desenvolver o trabalho socioeducativo junto à família? "Eu pedi, dei um papelzinho, 'pede alguém da sua família pra vir falar comigo'. Até pra conversar com a família sobre isso!... Mas eu, até agora, não consigo" (Ewá).

Cabe destacar a complexidade no que diz respeito à participação juvenil em regiões periféricas na ocupação do tráfico, assim como a necessidade de se abordar este tema a partir das políticas de proteção social ao trabalho infantil ${ }^{13}$. A garantia de políticas socioassistenciais e de inclusão nesses casos é permeada de conflitos: embora haja recomendações internacionais ${ }^{14}$ e legislações nacionais $^{15}$ que orientam para o entendimento do tráfico como uma das mais graves formas de trabalho infantil. A condução dos casos raramente é dada a partir desta abordagem por operadores do Poder Judiciário e do campo socioassistencial, numa tendência crescente à imposição de medidas punitivas ${ }^{3}$. Cabe ainda mencionar que, quan- 
do ocorrem, os esforços de inclusão esbarram em recursos limitados no campo das políticas de proteção social aos jovens.

\section{História do filho de Sobá}

Aqui chamaremos de Oyá, nossa interlocutora, que relata uma história que acompanhou em uma reincidência na medida, do jovem Ajagunã, 18 anos, negro, filho de Sobá. "Tava em medida, aí ele foi apreendido novamente e retornou pra cá" (Oyá).

Em seu breve retorno à convivência familiar, Ajagunã se envolve no que Oyá chama de "uma situação", categoria êmica tratando de possíveis conflitos ou infrações, dos quais não se tem muita informação:

[...] E quando ele retorna, bem no início da medida, a mãe dele falece. A mãe dele morre. Só que tem toda uma situação em torno disso, ela tem um infarto, só que esse infarto se dá quando ela sabe de uma situação que tá sendo com ele. Porque ele havia sido pego por pessoas até então não identificadas. E nessa coisa de não saber o que tava acontecendo e tal, ela veio a enfartar, e ele foi preso (Oyá).

Oyá conta de seu envolvimento e de toda a equipe, que chegou a acompanhar a família para a realização do velório da mãe, tendo também de comparecer ao Fórum, em razão da prisão de Ajagunã:

[...] Ele foi preso, porque ele tinha 18 anos. Ele começou a cumprir a medida, foi apreendido novamente, foi pra Fundação Casa. Quando ele sai, com 18 já, e mesmo assim ele sai com L.A. Então como ele já tinha 18, ele foi pro CDP. E o que fica dessa história, pra resumir, é o que... É... tem um entendimento da família, e acho até que de parte da sociedade, de que esse menino é responsável pela morte da mãe. Porque a mãe enfartou, né? Dele também... Tem esse sentimento também (Oyá).

A noção de "nervoso", que tomamos de teóricos das ciências sociais ${ }^{16,17}$ parece fazer sentido nesse contexto, quando sintomas físicos e morais se entrelaçam mediante a "situação" na qual Ajagunã está implicado, levando ao colapso de Sobá, que então descobrimos ser a verdadeira protagonista desta história.

[...] Eu fui pesquisar pra entender as questões do infarto, o que provoca. Você precisa, falta de qualidade de vida, de uma boa alimentação, de uma boa moradia, tudo isso! Aí você vive toda uma vida dessa, de pobreza, de vulnerabilidade social, ter que enfrentar o cárcere, ter que passar visita vexatória. Tudo isso, o olhar da sociedade em cima dessa pessoa (Oyá).
"Fico pensando", prossegue o relato, "Quanto essa mulher já estava sendo assassinada aos pouquinhos, por tudo isso que já vinha passando? Tanto com esse filho, como com outras questões" (Oyá).

Entre essas questões, o desemprego, o cárcere, e a política de benefícios sociais, conforme relatou Oyá, acompanhada de outra profissional que também acompanhou o caso, aqui chamada de Iemanjá:

O desemprego assolava parte da família intei$r a$, praticamente. Tinha [...] que lidar com o desemprego, e mais membros da família no cárcere... Qualquer pessoa mais conservadora vai dizer, "é uma família, então, que já é problemática, que já é do crime, porque tem mais pessoas envolvidas". Mas eu olho pra isso, entendo o contrário. Que sistema é esse? Tão cruel, que faz com que mais membros de uma família tenham que passar pelo cárcere. Inclusive a matriarca dessa família vem a falecer por conta disso. Porque, pra mim, ela foi assassinada. O Estado matou essa mulher. Ela não simplesmente morreu (Oyá).

Iemanjá completa o relato: "Ela tava sob avaliação do INSS. Ela tava morrendo de medo" (Iemanjá).

As técnicas explicam que Sobá teve um câncer quando Ajagunã ainda era recém-nascido. Em seus dois primeiros anos de vida, fora criado por outras pessoas, pois a mãe enfrentava as consequências de uma grave doença. "Em razão disso, ela recebia um benefício do INSS, e naquele período, ia passar por uma reavaliação desse benefício" (Oyá).

Sobá passava por dificuldades e muitas preocupações, principalmente no que cabia seu sustento e de sua família: "E se perde esse benefício?". O sustento familiar, num contexto sistêmico de desemprego, baseava-se na renda gerada a partir desse benefício, conforme contam as profissionais, "a renda da família inteira era essa", e, a qualquer tempo, poderia ser retirado:

[...] Eu vejo dessa maneira, essa mulher foi assassinada, foi executada, sim, por esse Estado! O Estado que éperverso. Que quando é presente, é pra punir. Vou comparar até com um pai que éausente, que quando é presente, ele pune (Oyá).

A partir de seu argumento, o Estado passa pela compreensão em diferentes dimensões, tomamos sua metáfora "paternal", levando a diferentes consequências: é um pai que administra mal seus recursos; é um pai punitivo; e é um pai ausente. No primeiro aspecto, mantém um benefício que não dá conta das reais necessidades da família, como o acesso ao trabalho e renda 
a seus membros e a programas de inclusão; ao mesmo tempo em que busca o controle (pela vida institucionalizada dessa família), não sabe como gerir seus investimentos e recursos (mantém o benefício como um arranjo substitutivo a políticas de inclusão social). É punitivo, oferece constantes ameaças (do corte de benefícios, das penalidades pelo descumprimento das regras), manifesta-se em tempo para reprimir "situações", e tem o cárcere como principal medida para enfrentamento da violência e da pobreza. É enfim um "pai ausente", não só com a família, mas com suas políticas previdenciárias e sociais e com os trabalhadores que as executam, parece não dar conta dos recursos de reinserção social (Ajagunã cumpria reincidência infracional quando foi de novo aprisionado), demonstrando a necessidade de investimento e de ofertas de recursos para as políticas socioeducativas de meio aberto. O Estado tem condutas ambíguas, assumindo diversas "faces" para a família de Ajagunã e Sobá, entre elas, a da institucionalização e a afetiva, da medida em meio aberto, mas também a do controle e da morte.

\section{Estado e desdobramentos do poder, biopolítica e questão racial}

A noção de biopolítica advém da obra foucaultiana ${ }^{13-15}$, e trata do desenvolvimento de métodos de gestão, próprios à Modernidade, que remetem aos primórdios do pensamento liberal. Localiza-se historicamente a existência de um raciocínio próprio ao governar - a governamentalidade -, que implica a soberania do Estado, e incorpora os conceitos biológicos enquanto processos políticos ${ }^{15}$.

Posteriormente, o autor retoma o conceito de biopolítica para tratar de uma teoria da soberania, que se desenvolve na modernidade e cujas concepções serviram sobre as guerras e sobre a questão racial. Nesta teoria, destaca-se, "a vida e a morte não são desses fenômenos naturais, imediatos, de certo modo originais ou radicais, que se localizariam fora do campo do poder politico"13. Segundo essa perspectiva, na organização jurídica e teórica de uma soberania, "em relação ao poder", aqueles estabelecidos enquanto "súditos” não são "em pleno direito", "nem vivo(s) nem morto(s)". No controle biopolítico, “é simplesmente por causa do soberano que o súdito tem direito de estar vivo ou [...] de estar morto"13. Foucault denomina uma dissimetria de direitos, uma vez que o poder soberano se exerce a partir "do direito de matar". A relação de soberania estudada por Foucault verifica a emergência, entre os séculos XVIII e XIX, de tecnologias, disciplinas (os campos de saber) e instituições de controle direcionadas, tanto aos corpos dos indivíduos, como voltadas ao todo populacional, "a segurança do conjunto em relação aos seus perigos internos"13.

É importante destacar que Foucault insere o conceito de biopolítica no contexto do estudo da modernidade, pensando nas possibilidades de leituras sobre a sociedade contemporânea, sob a égide do capitalismo liberal. Entende que as tecnologias e técnicas de gestão de corpos também se aplicarão à gestão de populações. "Agora que o poder é cada vez menos o direito de fazer morrer e cada vez mais o direito de intervir para fazer viver" ${ }^{\prime 3}$. Esse movimento tende a gradualmente se converter numa relação soberana que aos poucos de desvencilha, embora não completamente, de sua função de "fazer morrer", e assume o "fazer viver" e o "deixar morrer" como estratégias ${ }^{13-15,18-20}$.

No entanto, a soberania biopolítica não se desfaz completamente de seu potencial em "fazer morrer", assumindo para si propostas de suposto embasamento biológico como teorias de higienismo e racismo. "Em linhas gerais, o racismo, acho eu, assegura a função de morte na economia do biopoder"13.

Agamben ${ }^{18}$ retoma os conceitos de biopolítica a partir da leitura de Foucault, compreendendo os cenários da "morte" e da "vida" em disposição ao campo jurídico e à política. Percebe que essa noção produz vidas que somente se constituem “em exclusão" ou "em oposição", externas à legitimidade estabelecida juridicamente pelo Estado, definidas pelo conceito extraído do direito romano de "homo sacer". O autor apresenta-nos o conceito de "vidas nuas", estas emergem do lado oposto às proteções políticas, facilmente configurando-se "vidas matáveis"18 pelo Estado.

O racismo surge, nesse contexto da modernidade, a partir de construções discursivas de povos "perigosos" ou "infiltrados"19 nas dinâmicas populacionais.

Pensando os contextos locais, no que cabe à juventude negra de São Paulo, pensamos nos mecanismos que a inserem pelas margens na organização urbana, na produção de um grupo político social ${ }^{19,20}$ que apresenta uma faixa etária coincidente, residem nas periferias de uma grande região metropolitana, e são também potencialmente controlados e identificados e regulados pela ação do Estado, por meio de seus agentes policiais e instituições, sendo os mais atingidos pelas dimensões de violência e letalidade ${ }^{4,5}$. 
Wacquant ${ }^{21,22}$ é um autor que trata da desmobilização do Estado de bem-estar social (welfare). Tendo este processo como referência, podemos pensar no contexto atual de São Paulo e do Brasil, onde, ao mesmo tempo em que há redução dos investimentos em políticas sociais, ocorre um acirramento de discursos e propostas punitivas de todas as ordens, na condução das políticas de inclusão/exclusão, acesso/restrição, o que certamente tem efeitos na geografia das desigualdades sociais. Wacquant denomina tais propostas enquanto "prisonfare"22, implicando no investimento em políticas públicas de fundo repressor e punitivo, e, assim como as políticas sociais, seu objetivo é intervir e regular sobre a população e os corpos dos pobres.

No entanto, uma transição completa de um modelo de bem-estar social para um modelo penal não ocorre, produzindo as políticas de "dupla disciplina" ${ }^{\text {"22 }}$, dadas pela vigência simultânea dessas propostas. Essa dupla disciplina explicita-se na história do filho de Sobá, onde políticas previdenciárias e políticas de assistência social se evidenciam por meio de um desinvestimento, num curso de transição para as medidas repressivas, seja pelo sistema socioeducativo ou pela via do cárcere.

Das e Poole ${ }^{23,24}$ apontam que "a relação entre a violência e as funções ordenadoras do Estado é a chave para o problema das margens". Para essas autoras, a legitimidade do Estado se dá como resultado da demarcação de seus limites em relação às suas margens. As práticas do Estado territorializam e localizam estratégias de controle, em lugares que não são "meramente territoriais", são também "lugares de prática onde a lei e outras práticas estatais são colonizadas mediante outras formas de regulação que emanam das necessidades prementes das populações" ${ }^{24}$. A relação entre soberania e formas disciplinares de poder conformam as concepções acerca das margens do Estado.

Nos discursos, o histórico de ocupação e desenvolvimento dos territórios periféricos se associa aos cenários da pobreza estruturante, ao qual subscrevem os SMSE/MA com os quais dialogamos. Nestes, a informalidade das ofertas de trabalho e renda, assim como a insuficiência dos recursos de inclusão assistencial formam um paralelo com práticas de trabalho informal, desde o trabalho nas lavanderias às margens da Represa, assim como expedientes de mendicância e comércio nos transportes e o tráfico.

\section{Poder, poderes, Estado, agentes do Estado, Estados}

Retomando Foucault, este nos descreve uma noção de Estado/poder que não passa por um corpo integralmente consolidado, coeso, homogêneo, o autor nos apresenta o conceito de capilaridade, a partir do qual Estado/poder nem sempre será exercido irradiado de cima pra baixo, ou seja, imposto numa direção vertical, e confronta resistências e conformidades nesse percurso ${ }^{15}$.

Ao tratar do poder, suas conformidades, irradiações e resistências, Foucault argumenta por uma capilaridade de poder(es), pela qual, para além do Estado, existem agentes e agências que exercem, disputam, ocupam, deslocam os usos do poder - jogos de poder. Assumindo essa premissa, encontramos nos discursos e narrativas representações das relações de poder, - os relatos utilizam principalmente o termo "o Estado", que organizam sentidos muitas vezes divergentes sobre "o Estado" e o exercício de poder.

O poder aparece nos discursos da pesquisa denominado como Estado, e fala de seus possíveis agentes e agências que em alguma medida utilizam de possibilidades de poder. Nossos interlocutores, eles mesmos, também são trabalhadores que representam uma instância de ação do Estado - a que desenvolve o trabalho socioeducativo em meio aberto junto a jovens implicados em contextos de conflito com a lei. Os mesmos relatam outros agentes que circulam a representatividade do Estado (o poder policial ou o Poder Judiciário, por exemplo, assim como, o trabalho socioeducativo em meio fechado), além de outros discursos que concorrem com seu entendimento sobre condutas junto aos jovens, com os quais precisam tratar.

Ainda, outras expressões do Estado se revelam pelo trabalho desenvolvido junto a outros serviços - também representativos do Estado, como a saúde, a educação, ou até mesmo de outros programas de assistência social. No relato da história de Onira, isto se evidencia no trânsito difícil junto à Unidade de Saúde, e possíveis negliências da parte desta, assim como, nas tratativas sem sucesso para inclusão da jovem no PBF.

É comum nos relatos a frase "a falta do Estado”, para tratar de uma proposição do Estado que não se dá pela via da inclusão dos sujeitos e seu reconhecimento cidadão, mas em omissões e negligências, identificadas pelos nossos interlocutores como sistemáticas.

Os relatos falam de um "Estado" que são "os Estados”, que são seus agentes e suas agências, são 
aqueles que utilizam dos meios de poder de alguma forma em relação ao sistema socioeducativo. Compondo também um sistema de ambiguidades de práticas, saberes, condutas e discursos. $\mathrm{O}$ Estado apresenta sua face protetiva que convive ou resiste com um regime discursivo de austeridade, nos dá a impressão, em alguns registros, de um Estado "sob ameaça" do Estado, ou dos Estados. Ameaça que muitas vezes se confirmam por meio do "abandono" de funções de promoção de direitos/ protetivas, a partir da precarização. O Estado "bate à porta" do jovem de periferia argumento em conformidade com as entrevistas, com a missão, antes de tudo, de punir, e contraditoriamente, por meio dessa via de punição, pode, tardiamente, incluir jovens e famílias negras, pobres, moradoras de periferias, em programas e políticas sociais.

São, muitas vezes, diversas e divergentes, e até mesmo concorrentes, as faces de Estado que se apresentam aos jovens de que falam nossos interlocutores.

\section{Possíveis relações com o campo da saúde pública}

O campo de conhecimento da Saúde Pública e Coletiva é identificado com características acadêmico-científicas, historicamente, multidisciplinares ${ }^{25}$. A interlocução junto aos saberes das chamadas Ciências Sociais, Ciências Sociais aplicadas e humanidades não é novidade nas pesquisas em saúde, porém, conforme Ianni, "como campo científico, com circunscrição de objetos próprios e esforços de sistematização normativos e vinculantes, sim" 26 .

Associada à emergência de objetos e métodos de sistematização, identifica-se o aumento de temas de pesquisa "de interesse das Ciências Sociais e Saúde" ${ }^{\text {"7,28, }}$, como estudos sobre as políticas, sistemas e instituições de saúde, críticas aos modelos de saúde-doença e modelo biomédico, além do aumento significativo de temas relativos aos movimentos sociais, questões de gênero e sexualidades, violência, etc. Ocorre, de fato, uma produção que torna os objetos de reflexão como limítrofes, o que indica também a necessidade de mudança da perspectiva dos campos de conhecimento tradicionais das ciências da saúde em sua relação, não só com as ciências sociais e humanas, mas com a sociedade.

Esta preocupação pode ser compreendida, entre outras, pelas discussões acerca do conceito de transição demográfica e epidemiológica ${ }^{29,30}$ que acompanha mudanças nos padrões de mortali- dade e adoecimento das sociedades, mudanças fortemente associadas às transições demográficas e socioeconômicas que constituem o complexo da modernização. O estudo desses modelos indica diferentes tendências, em curso em diversos países em desenvolvimento, como no Brasil.

No país, este é marcado, não somente pelo ressurgimento de doenças infectocontagiosas, então controladas, como por exemplo, a sífilis, o aumento de mortalidade por doenças crônicas nãotransmissíveis (como exemplo, condições como hipertensão, os cânceres, entre outros agravos) e o aumento significativo dos índices de morte da população por violência (homicídios e suicídios) além de acidentes. Entendemos que as ciências humanas e sociais dispõem de importantes instrumentos de leitura e discussão para essas questões, aumentando as possibilidades interpretativas.

Acompanhamos, a partir dos relatos, histórias, como as de Onira e a do filho de Sobá, que dizem respeito a essa transição em curso, pensada pelas ciências da saúde, mas também, a partir de referenciais mais amplos, relacionada a transformações em perspectiva na sociedade, que apontam para questões e conflitos sociais, e relacionam o campo da saúde e das políticas sociais.

Finalmente, a respeito da necessidade de compreensão das interfaces da saúde pública com as políticas sociais, e o reconhecimento da saúde pública enquanto política social, por seu potencial de formação de "referenciais éticos e valorativos da vida social", uma vez que políticas de saúde impulsionam "um processo de apropriação, redefinição e produção de significados sociais", produzindo "impactos reais na estrutura social"31. Discutir as políticas de proteção social é discutir noções de cidadania.

\section{Considerações finais}

\section{Os vínculos}

A fala extraída do relato de outra profissional, a quem chamaremos Obá, encerra mais algumas questões, com as quais gostaríamos de concluir as discussões ora apresentadas:

[...] Acho que pra quem quer atuar (com SMSE/MA) ou até mesmo pesquisar, tem que se esvaziar, tem que vir com o cálice vazio. Deixar sua moral, seus costumes, seus ideais, tem que deixar tudo lá fora. Pra respeitar as famílias, porque a família tem uma história, tem uma vivência... A forma como você vai lidar com a história, que não são "problemas", como a gente já ouviu, não são 
números, como dado aí pelo Estado, são pessoas, estão vivas, têm histórias, ela (a família) chegou aqui num momento, mas até ela chegar aqui tem toda uma trajetória de vida (Obá).

Assinalamos deste relato algumas possibilidades de discussão. Entre elas, sobre os atravessamentos morais pelos quais o campo da medida socioeducativa passa. Ainda, uma necessidade que se impõe da compreensão dos sujeitos para além de suas passagens infracionais. Também nos relata que há arranjos familiares que ultrapassam os modelos compreendidos como "padrões", e os trabalhadores das políticas sociais lidam com esses diferentes arranjos, mais do que isso, parecem participar de alguma forma buscando também seu lugar nesses arranjos. Finalmente, chama a atenção para as políticas de narratividade que ora resgatamos, mais que "problemas de pesquisa", "estudos de caso", ou opções que atendam a um regime de produção de verdade, seja nos dispositivos do Estado, (como "números", ou "pra quem quer atuar”), seja na produção acadêmica, (como "problemas", ou "pra quem quer pesquisar"), tratamos com histórias de vida que ultrapassam o escopo de nossos discursos. Conforme a proposta de Passos e Benevides , a expressão de conhecimento que fazemos não apenas como "um problema teórico, mas um problema político"7.

As histórias, produzidas a partir do trabalho das equipes, para além do previsto no escopo das políticas socioassistenciais, representam também os vínculos que esses profissionais e equipes de- senvolvem e o desempenho de um papel nos diferentes arranjos e organizações familiares.

As histórias falam a respeito de questionamentos, de afetos, dissabores, desafios diante de um cenário de poucos recursos interventivos frente a graves questões colocadas pelas dinâmicas da sociedade e pelo Estado. Sobre a recusa de redução do trabalho aos mecanismos burocráticos, sobre o afeto e identificação com os sujeitos.

Acompanhamos a proposta do antropólogo João Biehl ${ }^{10}$, quando este nos interpela a: "achar maneiras de criar com os nossos sujeitos e a partir deles novas figuras do pensamento", e nos desafia a "contar histórias com devires humanos". Seguindo este intento, todos os personagens que são contados nessas histórias (e até um que é, também, contador) falam, não apenas da execução de políticas sociais, como de relações e devires.

O que emerge como inesperado neste campo é, certamente, o aspecto afetivo que mobiliza nossos interlocutores no desempenho de suas funções. O olhar, a escuta e a sensibilidade, a disponibilidade que ofertam aos jovens e famílias, a participação em suas vidas apresentam-se como uma disposição em estar juntos, "alguém com quem contar" 32 . O envolvimento com os jovens e famílias, que muitas vezes se entrelaça nas instituições familiares, compartilhando suas questões, em nome de uma configuração de vínculos sociais que, em nossa perspectiva, é uma resposta interessante a estratégias encarceradoras. 


\section{Referências}

1. Brasil. Lei $n^{\circ} 8.069$, de 13 de julho de 1990. Dispõe sobre o Estatuto da Criança e do Adolescente e dá outras providências. Diário Oficial da União 1990; 13 jul.

2. Brasil. Lei ${ }^{\circ} 12.594$, de 18 de janeiro de 2012. Institui o Sistema Nacional de Atendimento Socioeducativo (Sinase), regulamenta a execução das medidas socioeducativas destinadas a adolescente que pratique ato infracional. Diário Oficial da União 2012; 18 jan.

3. Carvalho DSC. Quando o Estado bate à porta - faces do Estado e narrativas sobre a juventude no atendimento socioeducativo na Zona Sul de São Paulo [tese]. São Paulo: Universidade de São Paulo; 2019.

4. Cerqueira D, Lima RS, Bueno S, Valencia LI, Hanashiro O, Machado PHG, Lima AS. Atlas da Violência 2017. Rio de Janeiro: IPEA; FBSP; 2017.

5. Santos LIC, Oliveira AM, Paiva IL, Yamamoto OH. Juventude e violência: trajetórias de vida e políticas públicas. Estud Pesqui Psicol 2012; 12(2):521-538.

6. Foucault M. A Ordem do Discurso. $21^{\text {a }}$ ed. São Paulo: Edição Loyola; 1996.

7. Passos E, Benevides RB. Por uma política da narratividade. In: Passos E, Kastrup V, Escóssia, L organizadores. Pistas do método da cartografia - Pesquisa-intervenção e produção de subjetividade. Porto Alegre: Sulina; 2015.

8. Barbosa M. A narrativa, a experiência e o acontecimento fundador de novos regimes de visibilidade da TV brasileira. Tempo 2004; 9(17):1-20.

9. Benjamin W. Magia e técnica, arte e política: ensaios sobre literatura e história da cultura - Obras escolhidas volume 1. $3^{\mathrm{a}}$ ed. São Paulo: Brasiliense; 1994.

10. Schuch P. Antropologia, entre o inesperado e o inacabado: entrevista com João Biehl. Horizontes Antropológicos (UFRGS) 2016; 22:389-423.

11. Biehl J. Antropologia do devir: psicofármacos - abandono social - desejo. RA 2008; 51(2):413-449.

12. Brasil. Ministério da Saúde (MS). Secretaria de Vigilância em Saúde. Boletim Epidemiológico: Sífilis 2017. Brasília: MS; 2017.

13. Foucault M. Em defesa da sociedade: curso no Collège de France (1975-1976). São Paulo: Martins Fontes; 1999.

14. Foucault M. A arqueologia do saber. $7^{\mathrm{a}}$ ed. Rio de Janeiro: Forense Universitária; 2008.

15. Foucault M. Microfísica do Poder. $28^{\mathrm{a}}$ ed. Rio de Janeiro: Edições Graal; 2010.

16. Duarte LFD. Da vida nervosa (nas classes trabalhadoras urbanas). Rio de Janeiro: Jorge Zahar; 1986.

17. Pelúcio LM. Abjeção e desejo: uma etnografia travesti sobre o modelo preventivo de aids. São Paulo: Annablume-Fapesp; 2009.

18. Agamben G. Homo sacer: o poder soberano e a vida nua. $2^{\text {a }}$ ed. Belo Horizonte: Editora UFMG; 2007.

19. Ribeiro IG, Benelli SJ. Jovens negros em conflito com a lei e o racismo de Estado. RIDH 2017; 5(1):245-262.

20. Mbembe A. Necropolítica. Arte Ensaios 2017; 32:122151.
21. Wacquant L. Punir os pobres: a nova gestão da miséria nos Estados Unidos. $2^{\mathrm{a}}$ ed. Rio de Janeiro: Revan; 2003.

22. Wacquant L. A política punitiva da marginalidade: revisitando a fusão entre workfare e prisonfare. Rev EPOS 2012; 3(1):1-28

23. Das V, Poole D. Anthropology in the Margins of the State. Oxford: School of Amercian Reserach Press, 2004.

24. Das V, Poole D. El estado y sus márgenes. Etnografías comparadas. Cuad Antropol Soc 2008; 27:19-52.

25. Russo JA, Carrara SL. Sobre as ciências sociais na Saúde Coletiva - com especial referência à Antropologia. Physis 2015; 25(2):467-484.

26. Ianni AMZ. O campo temático das ciências sociais em saúde no Brasil. Tempo Soc 2015; 27(1):13-32.

27. Canesqui AM. As Ciências Sociais e Humanas em Saúde na Associação Brasileira de Pós-graduação em Saúde Coletiva. Physis 2008; 18(2):215-250.

28. Canesqui AM. Ciências Sociais e Saúde no Brasil: Três Décadas de Ensino e Pesquisa. Cien Saude Colet 1998; 3(1):131-168.

29. Araujo JD. Polarização epidemiológica no Brasil. Epidemiol Serv Saude 2012; 21(4):533-538.

30. Duarte EC; Barreto SM. Transição demográfica e epidemiológica: a Epidemiologia e Serviços de Saúde revisita e atualiza o tema. Epidemiol Serv Saude 2012; 21(4):529-532.

31. Fleury S, Ouverney, AM. Política de Saúde: uma política social. In: Giovanella L, Escorel S, Lobato, LVC, Noronha JC, Carvalho AI, organizadores. Políticas e Sistema de Saúde no Brasil. Rio de Janeiro: Editora Fiocruz/Centro Brasileiro de Estudos de Saúde; 2008.

32. Sposati A. Estudo da capacidade protetiva de famílias beneficiárias de Programas Federais de Transferências de Renda em regiões periféricas metropolitanas. Brasília: Ministério do Desenvolvimento Social e Combate à Fome; 2011.

Artigo apresentado em 31/05/2019

Aprovado em 19/12/2019

Versão final apresentada em 21/12/2019

Editores-chefes: Romeu Gomes, Antônio Augusto Moura da Silva 